\title{
Microbial activity, mineral authigenesis and fluid mixing in deep interstitial fluids off South- Western Australia (IODP Leg 369): A multi-isotope approach
}

M.E. Böttcher ${ }^{1}$, H.-J. Brumsack ${ }^{2}$, I. Schmiedinger ${ }^{1}$, T. M. Quan $^{3}$

${ }^{1}$ Leibniz IOW, Warnemünde, FRG

${ }^{2}$ ICBM, Oldenburg University, FRG

${ }^{3}$ Oklahoma State University, USA

Interstitial waters extracted from long sediment cores retrieved during IODP 369 were analysed for the stable water isotopic $(\mathrm{O}, \mathrm{H})$ composition to constrain hydrographic changes in this region prior to modern time and possible changes due to water-rock interaction and fluid mixing. Dissolved sulfate (SO4; $\mathrm{S}$, $\mathrm{O}$ isotopes), and sulfide were analyzed to characterize, in concert with concentration measurements, diagenetic microbial and water-rock interaction processes in the deep sulfur cycle. The results demonstrate substantial downcore variations in the water isotope composition. Net microbial sulfate reduction with depth was observed at all sites, but sulfate (SO4) was only found to be consumed completely, within the investigated core lengths at Site U1512, off southern Australia. Whereas associated S isotope fractionation is characteristic for medium range fractionation factors, the $\mathrm{O}$ isotope composition provides evidence for a much more complex $\mathrm{S}$ cycle at the several sites: At U1516, the O isotope composition of dissolved $\mathrm{SO} 4$ is equilibrated with pore water, although $\mathrm{SO} 4$ concentrations remain above $20 \mathrm{mM}$. This indicates a subterrestrial re-oxidative $\mathrm{S}$ cycle. At Site $\mathrm{U} 1513$, the $\mathrm{O}$ isotope composition remains out of isotope exchange equilibrium although $\mathrm{SO} 4$ falls below $20 \mathrm{mM}$, indicating that the net decrease in $\mathrm{SO} 4$ is essentially caused by gypsum precipitation at depth, which is induced by diagenetic liberation of dissolved Ca concentrations upon, for instance, dolomitization. 